\title{
Morphology-Controllable Synthesis of one-dimensional ZnO nanostructures on graphene oxide-based electrode and its enhanced electrochemical performance for supercapacitor application
}

\author{
Lihua Lin, XueLi Yao, Li Ma* \\ Department of Telecommunication and information, Xi'an University of Science and Technology, \\ Xi'an 710054, China \\ *E-mail: mary@xust.edu.cn
}

doi: $10.20964 / 2020.08 .88$

Received: 2 April 2020 / Accepted: 24 May 2020 / Published: 10 July 2020

Different morphologies of vertically aligned $\mathrm{ZnO}$ nanostructures were synthesized onto graphene oxide (GO) coated indium thin oxide (ITO) electrode by electrochemical technique and considered for supercapacitor application. The morphology of $\mathrm{ZnO}$ nanowires were successfully transformed and controlled into other morphologies like nanorods, nanocones and nanopillars by changing the applied current density and growth temperature. Structural and morphological studies indicated that the asgrown $\mathrm{ZnO}$ nanostructures were preferentially synthesized along the c-axis direction with hexagonal wurtzite structure. Cyclic voltammetry measurements of different morphologies of $\mathrm{ZnO}$ based electrodes confirms that cone-shaped $\mathrm{ZnO}$ nanostructures exhibited high specific capacitance of $463.7 \mathrm{~F} \mathrm{~g}^{-1}$ at 20 $\mathrm{mVs}^{-1}$ scan rate, which can be mainly associated with the higher specific surface area of $\mathrm{ZnO}$ nanocone electrodes than those of other morphologies.

Keywords: Graphene oxide; $\mathrm{ZnO}$ nanoconces; Supercapacitor application; Cyclic voltammetry; Electrochemical impedance spectroscopy

\section{$\underline{\text { FULL TEXT }}$}

(C) 2020 The Authors. Published by ESG (www.electrochemsci.org). This article is an open access article distributed under the terms and conditions of the Creative Commons Attribution license (http://creativecommons.org/licenses/by/4.0/). 